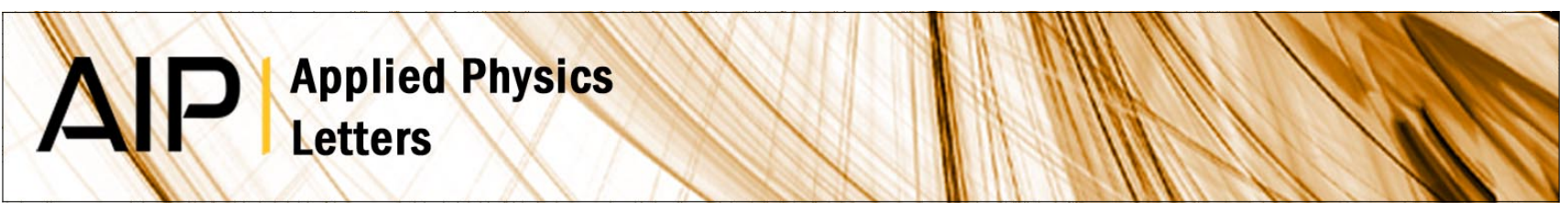

\title{
Fe/BaTiO3 interface: Band alignment and chemical properties
}

A. Zenkevich, R. Mantovan, M. Fanciulli, M. Minnekaev, Yu. Matveyev et al.

Citation: Appl. Phys. Lett. 99, 182905 (2011); doi: 10.1063/1.3657769

View online: http://dx.doi.org/10.1063/1.3657769

View Table of Contents: http://apl.aip.org/resource/1/APPLAB/v99/i18

Published by the American Institute of Physics.

\section{Related Articles}

Magnetic field induced metal-insulator transition in a kagome nanoribbon J. Appl. Phys. 110, 094306 (2011)

Evaluating the use of electronegativity in band alignment models through the experimental slope parameter of lanthanum aluminate heterostructures

J. Appl. Phys. 110, 093701 (2011)

Electronic level alignment at a metal-molecule interface from a short-range hybrid functional

J. Chem. Phys. 135, 164706 (2011)

Graphene p-n junctions with nonuniform Rashba spin-orbit coupling

Appl. Phys. Lett. 99, 162107 (2011)

The electronic structure of co-sputtered zinc indium tin oxide thin films

J. Appl. Phys. 110, 073711 (2011)

\section{Additional information on Appl. Phys. Lett.}

Journal Homepage: http://apl.aip.org/

Journal Information: http://apl.aip.org/about/about_the_journal

Top downloads: http://apl.aip.org/features/most_downloaded

Information for Authors: http://apl.aip.org/authors

\section{ADVERTISEMENT}

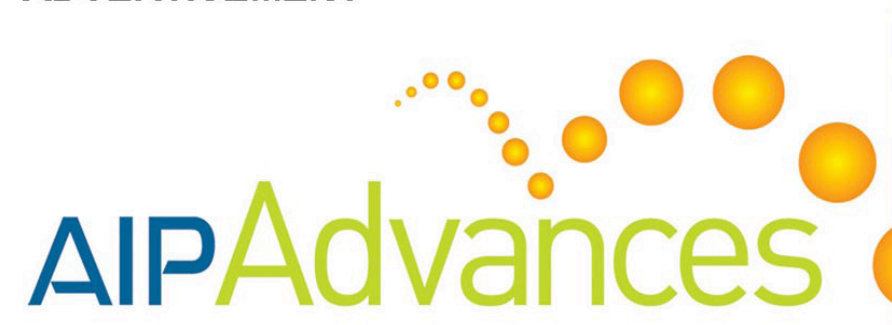

Submit Now

\section{Explore AIP's new \\ open-access journal}

Article-level metrics now available

Join the conversation!

Rate \& comment on articles 


\title{
$\mathrm{Fe} / \mathrm{BaTiO}_{3}$ interface: Band alignment and chemical properties
}

\author{
A. Zenkevich, ${ }^{1,2, a)}$ R. Mantovan, ${ }^{3}$ M. Fanciulli, ${ }^{3,4}$ M. Minnekaev, ${ }^{1}$ Yu. Matveyev, ${ }^{1}$ \\ Yu. Lebedinskii, ${ }^{1,2}$ S. Thiess, ${ }^{5}$ and W. Drube ${ }^{5}$ \\ ${ }^{1}$ NRNU "Moscow Engineering Physics Institute," 115409 Moscow, Russia \\ ${ }^{2}$ NRC “Kurchatov Institute," NBIC Center, 123182 Moscow, Russia \\ ${ }^{3}$ Laboratorio MDM IMM-CNR, I-20864 Agrate Brianza (MB), Italy \\ ${ }^{4}$ Dipartimento di Scienza dei Materiali, Università di Milano Bicocca, Milano, Italy \\ ${ }^{5}$ Deutsches Elektronen-Synchrotron DESY, D-22603 Hamburg, Germany
}

(Received 10 September 2011; accepted 12 October 2011; published online 3 November 2011)

\begin{abstract}
Ultrathin $\mathrm{BaTiO}_{3} / \mathrm{Fe}$ bi-layers were synthesized on $\mathrm{MgO}(001)$ and $\mathrm{SrTiO}_{3}(001)$ substrates by pulsed laser deposition in a single vacuum cycle. The full electronic band structure at the $\mathrm{Fe} /$ $\mathrm{BaTiO}_{3}$ interface has been determined by hard x-ray photoemission spectroscopy measurements. Depending on the growth conditions, the valence and conduction band offsets are found $3.05-3.26 \mathrm{eV}$ and $0.9-1.2 \mathrm{eV}$, respectively. Interface sensitive conversion electron Mößbauer spectroscopy demonstrates the absence of any magnetically dead layer thus proving that the determined band alignment is related to a sharp $\mathrm{Fe} / \mathrm{BaTiO}_{3}$ interface structure down to the atomic scale. (C) 2011 American Institute of Physics. [doi:10.1063/1.3657769]
\end{abstract}

The heterointerfaces between ferromagnetic (FM) and ferroelectric (FE) thin films have recently attracted much attention due to the magnetoelectric effects and their potential for the development of multifunctional devices. Among composite $\mathrm{FM} / \mathrm{FE}$ multiferroics, the $\mathrm{Fe} / \mathrm{BaTiO}_{3}$ (BTO) system is one of the most popular. ${ }^{1-7}$ The magnetoelectric effect at the Fe/BTO interface was first predicted by Duan et al. ${ }^{1}$ and attributed to changes of the interface magnetization upon the BTO electric polarization reversal. Electric manipulation of the Fe magnetic state was later observed in $10 \mathrm{~nm}$ Fe thin films deposited by pulsed laser deposition (PLD) on top of a BTO (100) single crystal, with a reported $20 \%$ change in the $\mathrm{Fe}$ coercive fields following the application of a $10 \mathrm{kV} / \mathrm{cm}$ electric field across the Fe/BTO structure. ${ }^{4}$ The inclusion of an ultrathin BTO tunnel barrier into Fe/BTO/ $\mathrm{La}_{\mathrm{x}} \mathrm{Sr}_{1-\mathrm{x}} \mathrm{MnO}_{3}$ magnetic tunnel junctions has been used to manipulate the FM magnetization by switching the FE polarization through the magnetoelectric coupling at the FM/BTO interface, ${ }^{6,7}$ thus providing the unique opportunity of controlling the spin-dependent transport properties with electric rather than magnetic fields. The $\mathrm{Fe} / \mathrm{BaTiO}_{3}$ system also allows the control of the magneto-crystalline anisotropy that determines the $\mathrm{Fe}$ magnetization orientation. ${ }^{2}$ Despite the high interest in the composite Fe/BTO multiferroic system, a full knowledge of the structural, chemical, and electronic interfacial structure is still lacking. In particular, the experimentally determined electronic band alignment for the $\mathrm{Fe} /$ BTO system has never been reported so far. In addition, the presence of magnetic "dead layers" has been reported at the $\mathrm{Fe} / \mathrm{BTO}$ interface, ${ }^{5}$ which can directly affect the spin polarization of tunneling electrons in functional devices including the $\mathrm{Fe} / \mathrm{BTO}$ stack.

In the present paper, the full electronic band alignment at the $\mathrm{Fe} / \mathrm{BTO}$ interface has been determined utilizing $\mathrm{x}$-ray photoemission spectroscopy (HAXPES), and the band gap

\footnotetext{
${ }^{\text {a) }}$ Author to whom correspondence should be addressed. Electronic mail: avzenkevich@mephi.ru.
}

values for the employed ultrathin BTO layers was directly measured by reflection electron energy loss spectroscopy (REELS). ${ }^{8}$ Atomic-scale and interface sensitive ${ }^{57} \mathrm{Fe}$ conversion electron Mößbauer spectroscopy (CEMS) demonstrates the absence of any magnetically dead layer at the Fe/BTO interface, thus proving that the proposed band structure is intrinsically related to a chemically pure $\mathrm{Fe} / \mathrm{BTO}$ system.

$\mathrm{Fe} / \mathrm{BTO}$ heterostructures were grown by PLD in a homemade setup with a base pressure of $p \approx 10^{-6} \mathrm{~Pa}$ on $\mathrm{MgO}(001)$ and $\mathrm{SrTiO}_{3}$ (001) (STO) single-crystal substrates by using a YAG:Nd laser $(\lambda=1064 \mathrm{~nm})$ operating in the Q-switched regime $(\tau=15 \mathrm{~ns})$ with the variable output energy $\mathrm{E}=50 \div$ $200 \mathrm{~mJ}$ and repetition rate $v=5-50 \mathrm{~Hz}$. Both $\mathrm{Fe} / \mathrm{BTO}$ and $\mathrm{BTO} / \mathrm{Fe}$ types of interfaces were formed in order to investigate the effect of the growth conditions on the interface properties. The BTO films $(2-15 \mathrm{~nm})$ were grown from the sintered stoichiometric $\mathrm{BTO}$ target at $\mathrm{T}=450{ }^{\circ} \mathrm{C}$ and further annealed at $\mathrm{T}=450^{\circ} \mathrm{C}$ either in residual vacuum $(\sim 5$ $\times 10^{-6} \mathrm{~Pa}$ ) or under $\approx 1 \mathrm{~Pa}$ of oxygen pressure, indicated in the following with $\mathrm{BTO}_{\mathrm{V}}$ and $\mathrm{BTO}_{\mathrm{O}}$, respectively. Epitaxial $\sim 10 \mathrm{~nm}$ thick $\mathrm{Fe}$ layers were grown in ultrahigh vacuum (UHV) at $\mathrm{T}=250^{\circ} \mathrm{C}$ on $\mathrm{MgO}$ (001) substrates. In order to perform an interface-sensitive CEMS analysis, isotopically enriched ${ }^{57} \mathrm{Fe}$ and ${ }^{54} \mathrm{Fe}$ targets were used during PLD to form an ultrathin $(\sim 2 \mathrm{~nm}){ }^{57} \mathrm{Fe}$ Mossbauer-active tracer layer in contact with BTO. Alternatively, Fe was deposited on top of epitaxial/polycrystalline BTO film grown on STO(001). The structural properties as well as the ferroelectric nature of asgrown ultrathin BTO layers in contact with Fe have been reported elsewhere. ${ }^{8}$

The electronic band line-up at the Fe/BTO interface is determined from synchrotron HAXPES data obtained using instruments at beamlines BW2 (DORIS III) and P09 (PETRA III) at DESY (Hamburg, Germany). The adopted photon energy of $\mathrm{E}=6 \mathrm{keV}$ enables to probe layers up to $20 \mathrm{~nm}$ depth, thus providing the opportunity to investigate the electronic properties at the buried Fe/BTO interfaces, even in the presence of a continuous capping metal layer. 


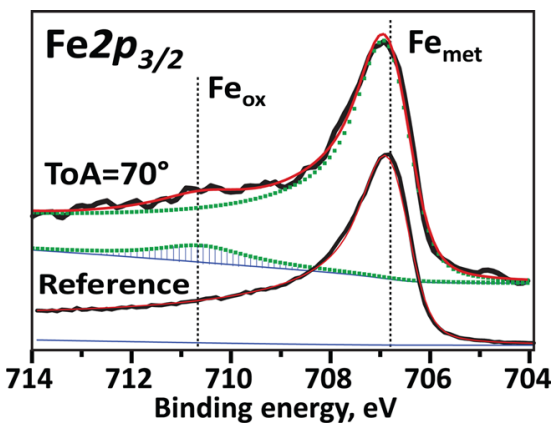

FIG. 1. (Color online) HAXPES Fe $2 p_{3 / 2}$ core level spectrum of a $\mathrm{BTO}_{\mathrm{V}}(5 \mathrm{~nm}) / \mathrm{Fe}(12 \mathrm{~nm}) / \mathrm{MgO}$ sample at $70^{\circ}$ electron take-off angle fitted with the asymmetric line of a bulk Fe also given as a reference.

Photoemission spectra at variable take-off angle (ToA) are taken in order to analyze the chemical state of the Fe underlayer in contact with BTO. The spectrometers were calibrated with the $\mathrm{Au} 4 f$ line at $\mathrm{BE}_{\mathrm{Au} 4 f}=84.0 \mathrm{eV}$. The UNIFIT software is used to fit the experimental data.

Figure 1 shows the HAXPES $\mathrm{Fe}_{2 p 3 / 2}$ lines acquired from $\mathrm{BTO}_{\mathrm{V}}(5 \mathrm{~nm}) / \mathrm{Fe}(12 \mathrm{~nm}) / \mathrm{MgO}$ sample at $70^{\circ} \mathrm{ToA}$ along with the reference spectrum from the surface of a bulk $\mathrm{Fe}$ sample cleaned in situ by the $\mathrm{Ar}^{+}$ion sputtering for $90 \mathrm{~min}$. in UHV. The typical Fe line centered at $706.76 \pm 0.05 \mathrm{eV}$ is observed at the $\mathrm{BTO}_{\mathrm{V}} / \mathrm{Fe}$ interface. In order to account for its intrinsic asymmetry, ${ }^{9}$ the $\mathrm{Fe} 2 p$ line was fitted with the Doniac-Sunjic function. ${ }^{10}$ The Tougaard background model ${ }^{11}$ has been employed as an alternative to the Shirley background for transition metals and is, therefore, especially suited for asymmetrical signals. The asymmetry parameter $\alpha \approx 0.38$ was thus deduced from the fitting of the recorded reference bulk Fe line. Only few percent area contribution of the oxidized fraction with the binding energy $\mathrm{BE}=710.7 \pm 0.1 \mathrm{eV}$ is found in the $\mathrm{Fe} 2 p$ spectrum taken at the glancing $\left(70^{\circ}\right)$ take-off angle most sensitive to the Fe adjacent to the BTO layer on top (Fig. 1, upper spectrum). Therefore, based on the HAXPES analysis, we conclude a chemically sharp Fe/BTO interface. It is of interest to compare our results with the recently reported chemical properties of $\mathrm{Fe} / \mathrm{BTO}$ interface, where a $\sim 2 \mathrm{~nm}$ thick iron oxide (presumably $\mathrm{FeO}$ ) layer has been concluded at the $\mathrm{Fe} / \mathrm{BTO}$ single crystal interface from in situ XPS analysis. ${ }^{5}$ The different conclusions made by analyzing very similar XPS spectra result from the fact that in our analysis the core level $\mathrm{Fe} 2 p$ line shape is assumed to be intrinsically asymmetric as was pointed above.

In order to rule out the presence of any magnetically dead layer at the buried $\mathrm{BTO} / \mathrm{Fe}$ interface, CEMS has been performed

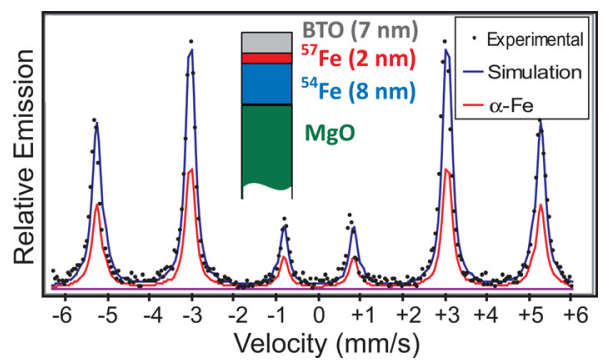

FIG. 2. (Color online) CEMS spectrum taken from $\mathrm{BTO}_{\mathrm{V}}(7 \mathrm{~nm}) /^{57} \mathrm{Fe}(2 \mathrm{~nm}) \rho^{54}$ $\mathrm{Fe}(10 \mathrm{~nm}) / \mathrm{MgO}(100)$ sample fitted with the characteristic $\alpha$-Fe magnetically split sextet.

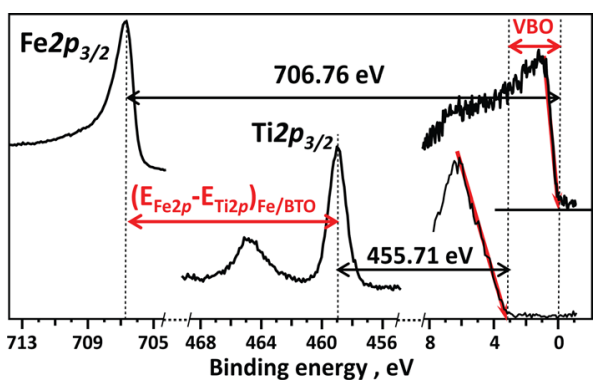

FIG. 3. (Color online) HAXPES spectra of a $\sim 15 \mathrm{~nm}$ thick BTO film grown in oxygen on a highly doped STO substrate, of a bulk Fe sample, as well as the illustration of VBO determination in a Fe/BTO bi-layer.

at room temperature by using a ${ }^{57} \mathrm{Co}$ radioactive source embedded in an Rh matrix, which is moved by a standard constant acceleration drive. A $\left.\mathrm{BTO}_{\mathrm{v}}(7 \mathrm{~nm})\right)\left.^{57} \mathrm{Fe}(2 \mathrm{~nm})\right|^{54} \mathrm{Fe}(8 \mathrm{~nm}) /$ $\mathrm{MgO}(001)$ sample is incorporated as an electrode in a He$\mathrm{CH}_{4}$ filled parallel-plate avalanche detector, which operates at $\sim 700 \mathrm{~V} .{ }^{12}$ As clearly shown in Fig. 2, no other contributions than the magnetically split sextet relative to $\alpha$-Fe (isomer shift of $0 \mathrm{~mm} / \mathrm{s}$ ) are observed at the $\mathrm{Fe} / \mathrm{BTO}$ interface. The Fe magnetic moments at the interface are aligned parallel to the sample's plane, as evidenced by the nearly perfect 3:4:1:1:4:3 line intensity ratio. The Fe magnetic moment is not changed when compared to the bulk Fe value, showing a hyperfine magnetic field value of $\mathrm{B}_{\mathrm{hf}} \sim 33 \mathrm{~T}$ for the ${ }^{57} \mathrm{Fe}$ sites in contact with BTO. At room temperature, paramagnetic phases such as $\mathrm{FeO}$ should be readily observed at the interface by CEMS, since they are represented by welldistinguishable doublets in a Mößbauer spectrum. ${ }^{13}$ By combining CEMS with HAXPES, we conclude that the chemical bonding at the $\mathrm{BTO}_{\mathrm{V}} / \mathrm{Fe}$ interface is characterized by the absence of either any magnetically dead layer or iron oxide, thus proving an abrupt Fe/BTO interfacial chemical structure down to the atomic scale. In order to determine the band line-up at the Fe/BTO interface, a well-known XPS-based technique has been employed by using the Kraut methodology. ${ }^{14}$ The valence band offset (VBO) in the Fe/BTO heterojunction is calculated according to Eq. (1):

$$
\begin{aligned}
V B O= & \left(E_{F e 2 p}-E_{T i 2 p}\right)_{F e / B T O}-\left(E_{F e 2 p}-E_{F}\right)_{F e} \\
& +\left(E_{T i 2 p}-V B M\right)_{B T O} .
\end{aligned}
$$

The energy difference $E_{F e 2 p}-E_{F}$ is measured on the clean surface of a $\mathrm{Fe}$ bulk sample and is found $E_{F e 2 p}-E_{F}$

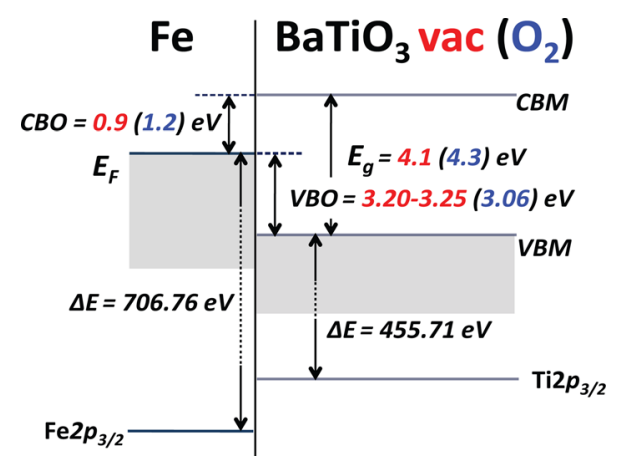

FIG. 4. (Color online) Summarized electronic band alignment diagram for Fe in contact with $\mathrm{BTO}_{\mathrm{V}}$ and $\mathrm{BTO}_{\mathrm{O}}$ (values in brackets). 
TABLE I. Measured XPS line separations, $E_{g}$ values, and calculated valence/conduction band offsets for different types of Fe/BTO heterojunctions.

\begin{tabular}{lcccc}
\hline \hline & $\begin{array}{c}\left(E_{F e 2 p}-E_{T i 2 p}\right)_{F e / B T O} \\
\pm 0.05 \mathrm{eV}\end{array}$ & $\begin{array}{c}\mathrm{VBO}, \\
\pm 0.05 \mathrm{eV}\end{array}$ & $\begin{array}{c}\mathrm{E}_{\mathrm{g}}, \pm 0.1 \mathrm{eV} \\
\text { (Ref. 8) }\end{array}$ & $\begin{array}{c}\mathrm{CBO}, \\
\pm 0.1 \mathrm{eV}\end{array}$ \\
\hline $\mathrm{MgO} / \mathrm{Fe} / \mathrm{BTO}$ & 247.85 & 3.20 & 4.1 & 0.9 \\
$\mathrm{STO} / \mathrm{BTO} / \mathrm{Fe}$ & 247.81 & 3.25 & 4.1 & 0.9 \\
$\mathrm{STO} / \mathrm{BTO} / \mathrm{Fe}$ & 248.00 & 3.06 & 4.3 & 1.2 \\
\hline \hline
\end{tabular}

$=706.76 \pm 0.05 \mathrm{eV}$ as shown in Figure 3. In the same figure, the $\mathrm{E}_{\mathrm{Ti} 2 p}$ line separation with respect to valence band maximum (VBM), as determined in a pure BTO film grown on a conducting (highly doped) STO substrate, is $\left(\mathrm{E}_{\mathrm{Ti} 2 p}-\mathrm{VBM}\right)_{\mathrm{BTO}}=455.71 \pm 0.05 \mathrm{eV}$. This value is in excellent agreement with previously reported data. ${ }^{15} \mathrm{We}$ note that for BTO films grown in vacuum the line separations are found to be the same within the experimental error (not shown). The line separation $\left(E_{F e 2 p}-E_{T i 2 p}\right)$ is determined from the spectra measured on a Fe/BTO bi-layer. Equation (1) can then be used to determine the VBO at different $\mathrm{Fe} /$ BTO interfaces. These values are given in Table I. The band gap of the employed ultra-thin BTO films has been previously determined by in situ REELS, ${ }^{8}$ and values $E_{\mathrm{g}}=4.1$ and $4.3 \mathrm{eV}$ are found for the films grown in vacuum and in $\mathrm{O}_{2}$, respectively. The obtained $\mathrm{E}_{\mathrm{g}}$ is much larger compared to the bulk BTO single crystal ${ }^{16}$ and consistent with the earlier reported effects of the BTO film thickness ${ }^{17}$ and/or grain size. ${ }^{18}$ By combining the HAXPES and REELS (Ref. 8) data (Table I), we can construct the full electronic band structure for the different types of $\mathrm{Fe} / \mathrm{BTO}$ interfaces. The summarized Fe/BTO electronic band line-up is shown in Figure 4.

Let us briefly discuss the observed differences in the electronic structure of $\mathrm{Fe} / \mathrm{BTO}$ interface depending on the growth conditions. First, we notice that the VBO in case of $\mathrm{Fe}$ in contact with $\mathrm{BTO}_{\mathrm{V}}$ is larger compared to that with $\mathrm{BTO}_{\mathrm{O}}$. This result corroborates the model describing the formation of the electric dipole at the metal/dielectric interface in terms of the charge (electron) transfer across the interface from the oxygen vacancies $\left(\mathrm{V}_{\mathrm{O}}\right)$ in the ferroelectric acting as donors to the metal once the work function of the metal is sufficiently large. ${ }^{19}$ Hence, the presumably very high $\mathrm{V}_{\mathrm{O}}$ concentration in $\mathrm{BTO}_{\mathrm{V}}$ results in a decrease of the "effective" work function of $\mathrm{Fe}$ in contact with $\mathrm{BTO}_{\mathrm{V}}$ giving rise to the larger VBO. Up to $0.3 \mathrm{eV}$, the change in the $\mathrm{Pt} /$ STO Schottky barrier height was predicted depending on the amount of $\mathrm{V}_{\mathrm{O}},{ }^{19}$ while similar calculations reveal up to $1 \mathrm{eV}$ for Pt/PZT system as a function of $\mathrm{V}_{\mathrm{O}}$ concentration. ${ }^{20}$ The obtained VBO difference between $\mathrm{Fe} / \mathrm{BTO}_{\mathrm{V}}$ and $\mathrm{Fe} / \mathrm{BTO}_{\mathrm{O}}$ of $\sim 0.2 \mathrm{eV}$ is well within this range. The smaller bandgap in $\mathrm{BTO}_{\mathrm{V}}$ compared to $\mathrm{BTO}_{\mathrm{O}}$ can also originate from the high $\mathrm{V}_{\mathrm{O}}$ concentration in the former. Assuming the energy levels of (both neutral and charged) oxygen vacancies lie in the upper part of the gap, and suggesting their very high concentration in $\mathrm{BTO}_{\mathrm{v}}$, they can eventually form a sub-band thus effectively decreasing the bandgap by $0.2 \mathrm{eV}$ compared to $\mathrm{BTO}_{\mathrm{O}}$. On the other hand, we observe no major differences between the $\mathrm{VBO}$ in $\mathrm{Fe} / \mathrm{BTOv}$ and the reversed $\mathrm{BTOv} / \mathrm{Fe}$ stack, thus confirming that the $\mathrm{V}_{\mathrm{O}}$ abundance in $\mathrm{BTO}$ is mainly responsible for setting the $\mathrm{VBO}$ at the $\mathrm{Fe} / \mathrm{BTO}$ interface.

In summary, we have determined the band line-up for the $\mathrm{Fe} / \mathrm{BaTiO}_{3}$ system. The absence of any spurious phase at the interface assures that the experimentally determined band alignment is related to a chemically pure $\mathrm{Fe} / \mathrm{BaTiO}_{3}$ interface structure. The experimental results reported here could help to calculate more precisely the tunneling probability in composite multiferroic systems including Fe/BTO, being of use for predicting the transport properties (i.e., the tunneling electroresistance) of ferroelectric and multiferroic tunnel junctions. The current data were obtained for nonpolarized $\mathrm{BaTiO}_{3}$ films. Further experiments are in progress in order to investigate the effect of the BTO polarization on the band alignment evolution at the Fe/BTO interface.

${ }^{1}$ C.-G. Duan, S. S. Jaswal, and E. Y. Tsymbal, Phys. Rev. Lett. 97, 047201 (2006).

${ }^{2}$ C.-G. Duan, J. P. Velev, R. F. Sabirianov, W. N. Mei, S. S. Jaswal, and E. Y. Tsymbal, Appl. Phys. Lett. 92, 122905 (2008).

${ }^{3}$ J. Lee, N. Sai, T. Cai, Q. Niu, and A. Demkov, Phys. Rev. B 81, 144425 (2010).

${ }^{4}$ S. Sahoo, S. Polisetty, C.-G. Duan, S. S. Jaswal, E. Y. Tsymbal, and C. Binek, Phys. Rev. B 76, 092108 (2007).

${ }^{5}$ S. Brivio, D. Petti, R. Bertacco, and J. C. Cezar, Appl. Phys. Lett. 98, 092505 (2011).

${ }^{6}$ V. Garcia, M. Bibes, L. Bocher, S. Valencia, F. Kronast, A. Crassous, X. Moya, S. Enouz-Vedrenne, A. Gloter, D. Imhoff, C. Deranlot, N. D. Mathur, S. Fusil, K. Bouzehouane, and A. Barthélémy, Science 327, 1106 (2010).

${ }^{7}$ S. Valencia, A. Crassous, L. Bocher, V. Garcia, X. Moya, R. O. Cherifi, C. Deranlot, K. Bouzehouane, S. Fusil, A. Zobelli, A. Gloter, N. D. Mathur, A. Gaupp, R. Abrudan, F. Radu, A. Barthélémy, and M. Bibes, Nature Mater. 10, 753 (2011).

${ }^{8}$ A. Zenkevich, M. Minnekaev, Yu. Lebedinskii, K. Bulakh, A. Chouprik, A. Baturin, R. Mantovan, M. Fanciulli, and O. Uvarov, "Pulsed laser deposition of ultrathin $\mathrm{BaTiO}_{3} / \mathrm{Fe}$ bi-layers: structural characterization and piezoelectric response," Thin Solid Films (to be published).

${ }^{9}$ V. M. Pessa, Phys. Rev. B 15, 1223 (1977).

${ }^{10}$ S. Doniach and M. Sunjic, J. Phys. C 3, 285 (1970).

${ }^{11}$ S. Tougaard and B. Jörgensen, Surf. Int. Anal. 7, 17 (1985).

${ }^{12}$ R. Mantovan and M. Fanciulli, Rev. Sci. Instrum. 78, 063902 (2007).

${ }^{13}$ E. Kuzman, S. Nagy, and A. Vértes, Pure Appl. Chem. 75(6), 801 (2003).

${ }^{14}$ E. A. Kraut, R. W. Grant, J. R. Waldrop, and S. P. Kowalczyk, Phys. Rev. Lett. 44, 1620 (1980).

${ }^{15}$ C. H. Jia, Y. H. Chen, X. L. Zhou, A. L. Yang, G. L. Zheng, X. L. Liu, S. Y. Yang, and Z. G. Wang, Appl. Phys. A 99, 511 (2010).

${ }^{16}$ S. H. Wemple, Phys. Rev. B 2, 2679 (1970).

${ }^{17}$ H. Guo, L. Liu, Zh. Chen, S. Ding, H. Lu, K. Jin, Y. Zhou, and B. Cheng, Europhys. Lett. 73, 110 (2006).

${ }^{18}$ Y. K. Vayunandana Reddy, D. Mergel, S. Reuter, V. Buck, and M. Sulkowski, J. Phys. D: Appl. Phys. 39, 1161 (2006).

${ }^{19}$ M. Dawber, K. M. Rabe, and J. F Scott, Rev. Mod. Phys. 77, 1083 (2005).

${ }^{20}$ M. Dawber and J. F Scott, Integr. Ferroelectr. 38, 161 (2001). 